\title{
TELEVISION PROGRAMMES IN THE ACQUISITION OF ENGLISH PRONUNCIATION
}

The study analyzes the influence of watching authentic TV programmes in English on the non-native speakers' level of English pronunciation. We tried to detect the correlation between frequency of watching TV programmes and perceptual analysis of English pronunciation of our respondents which was done by native speakers.

Key words: English pronunciation, authentic TV programmes, correlation.

\section{Introduction}

Pronunciation is one of the most difficult aspects of language for a student to learn and some of them wish, in a long-term perspective, to pronounce at the level native speakers operate at, or at least, to be as close to this level as possible, which may well be a crowning achievement for an English foreign learner. A foreign learner has a number of methods to choose from which may vary in many ways. There exist many extralingual and interlingual factors which influence our pronunciation. Each and every one of us has their own ability to acquire foreign language pronunciation. Psychological and biological factors may play a key role, but we must not forget to mention the methodological determinants of pronunciation learning and acquisition [1].

The relevant studies published so far, which were focused on the analysis of factors of foreign language phonic competence and performance, vary in several dimensions, such as subjects, objects, methods or processes of the research. In order to improve a learner's pronunciation, one must be determined to work rather hard. An individual imitates the pronunciation of another person mainly when they are positively identified with that person. The combination of feeling and thinking can increase the quality of perception and production; therefore, the relation to foreign language speakers and culture is of positively stimulating character. In our quasiexperiment we concentrated on watching TV programmes as one of the means to improve English pronunciation and we tried to find out whether the frequency of watching TV programmes correlates with one's pronunciation quality or not [2].

\section{Methodology}

We worked with a group of 26 people. All of them were first year students of English language and literature at the Faculty of Science at the University of Zilina. The perceptual analysis was made by five English native speakers. Three of them were Americans, one was Briton and one was Australian. Each of them was a professional English language teacher.

Each respondent produced a 1-minute spontaneous monologue in the English language, which was digitally recorded for perceptual analysis. The topic of utterances was autobiographical. In addition, the respondents were asked to fill in a questionnaire which focused on watching television programmes. The questionnaire was completed after the recording. Pronunciation quality of the respondents was evaluated by the native speakers who were using a perceptual evaluation method. The students were given a rating from one to five where five is considered to be an excellent pronunciation and one is thought to be a poor one (Table 1).

Scale of perceptual evaluation

Table 1

\begin{tabular}{|c|c|}
\hline Code & Evaluation of pronunciation \\
\hline 5 & excellent \\
\hline 4 & satisfactory \\
\hline 3 & good \\
\hline 2 & fair \\
\hline 1 & poor \\
\hline
\end{tabular}

\footnotetext{
* Zdena Kralova, Rastislav Metruk

Department of English Language and Literature, Faculty of Science, University of Zilina, Slovakia, E-mail: zdena.kralova@fpv.uniza.sk
} 
Questionnaire

The questionnaire was created to find out why and how often the students of English language watch authentic TV programmes in English. We coded the questionnaire data (frequency of watching) in a 5-point descending scale (Table 2).

Scale of frequency

Table 2

\begin{tabular}{|c|c|}
\hline Code & Frequency of watching \\
\hline 5 & every day \\
\hline 4 & two/three times a week \\
\hline 3 & once a week \\
\hline 2 & once in two weeks \\
\hline 1 & once a month \\
\hline
\end{tabular}

1. Do you watch any authentic television programmes in English (e. g. sit-coms, serials, films, news etc...)?

2. If so, how often?

3. Are you able to name some particular programmes you watch and some particular TV stations or other sources you watch these programmes on?

4. Do you usually watch programmes broadcast in British English, American English or other?

5. In case you watch these types of programmes, do you watch them with subtitles? If yes, write the name of the language the subtitles are in, please.

6. What is the reason you watch these programmes?

\section{Procedure}

1. We recorded spontaneous English monologues of each respondent. The average length of the utterances was 1 minute.

2. After the recording session, each respondent was asked to fill in the questionnaire.

3. Five English native speakers perceptually evaluated the recordings on a scale of 1 to 5 . An average evaluation for each respondent was calculated (Table 3).

4. We coded the questionnaire data (frequency of watching) on a scale of 1 to 5 (Table 3).

5. The pronunciation and frequency data were related by a simple correlation (Table 4).

At a level of significance 0.1 , for the group of 26 people, the relevant correlation coefficient is 0.260 .

6. We analysed additional data from the questionnaire (Figs 1-4).

\section{Results}

A simple correlation administered in Microsoft Excell by using function Correl (array1; array2) was used in order to calculate the correlation coefficient. The correlation coefficient which expresses the dependence of frequency of watching TV programmes and the level of pronunciation of the respondents $(0.1518)$ is lower than
Coding the perceptual analysis and questionnaire data

Table 3

\begin{tabular}{|c|c|c|c|c|c|c|c|}
\hline Respondent & $\mathrm{NS}_{1}$ & $\mathrm{NS}_{2}$ & $\mathrm{NS}_{3}$ & $\mathrm{NS}_{4}$ & $\mathrm{NS}_{5}$ & $\begin{array}{c}\text { Evaluation } \\
\text { mean }\end{array}$ & Frequency \\
\hline 1. & 3 & 4 & 3 & 3 & 4 & 3.4 & 1 \\
\hline 2. & 4 & 4 & 3 & 3 & 3 & 3.4 & 3 \\
\hline 3. & 4 & 3 & 4 & 3 & 3 & 3.6 & 5 \\
\hline 4. & 2 & 3 & 3 & 4 & 3 & 3 & 2 \\
\hline 5. & 3 & 3 & 3 & 3 & 3 & 3 & 4 \\
\hline 6. & 3 & 3 & 4 & 4 & 3 & 3.4 & 1 \\
\hline 7. & 3 & 3 & 2 & 3 & 3 & 2.8 & 3 \\
\hline 8. & 2 & 3 & 3 & 3 & 3 & 2.8 & 3 \\
\hline 9. & 4 & 3 & 3 & 3 & 3 & 3.2 & 5 \\
\hline 10. & 4 & 3 & 3 & 3 & 4 & 3.4 & 5 \\
\hline 11. & 5 & 3 & 4 & 5 & 4 & 4.2 & 2 \\
\hline 12. & 2 & 3 & 3 & 2 & 3 & 2.6 & 4 \\
\hline 13. & 2 & 3 & 2 & 3 & 2 & 2.4 & 3 \\
\hline 14. & 2 & 3 & 2 & 1 & 2 & 2 & 3 \\
\hline 15. & 5 & 4 & 5 & 5 & 5 & 4.8 & 5 \\
\hline 16. & 3 & 3 & 3 & 2 & 4 & 3 & 3 \\
\hline 17. & 2 & 3 & 4 & 3 & 3 & 3 & 4 \\
\hline 18. & 3 & 3 & 3 & 3 & 3 & 3 & 3 \\
\hline 19. & 3 & 3 & 3 & 4 & 3 & 3.2 & 5 \\
\hline 20. & 4 & 3 & 3 & 3 & 3 & 3.2 & 3 \\
\hline 21. & 3 & 2 & 3 & 2 & 3 & 2.6 & 3 \\
\hline 22. & 3 & 3 & 3 & 3 & 3 & 3 & 5 \\
\hline 23. & 3 & 3 & 3 & 3 & 2 & 2.8 & 3 \\
\hline 24. & 2 & 4 & 3 & 3 & 3 & 3 & 3 \\
\hline 25. & 3 & 3 & 3 & 2 & 3 & 2.8 & 3 \\
\hline 26. & 2 & 2 & 3 & 3 & 3 & 2.6 & 3 \\
\hline Mean & 3.04 & 3.08 & 3.12 & 3.04 & 3.12 & 3.08 & 3.35 \\
\hline
\end{tabular}

NS - English native speaker

the critical value for the group of 26 respondents at a level of significance $0.1(0.260)$. Therefore, the correlation is not evident and the relationship of analysed variables was not confirmed.

Correlation of pronunciation and frequency

Table 4

\begin{tabular}{|c|c|c|}
\hline Respondent & Pronunciation & Frequency \\
\hline 1. & 3.4 & 1 \\
\hline 2. & 3.4 & 3 \\
\hline 3. & 3.6 & 5 \\
\hline 4. & 3.0 & 2 \\
\hline 5. & 3.0 & 4 \\
\hline 6. & 3.4 & 1 \\
\hline 7. & 2.8 & 3 \\
\hline 8. & 2.8 & 3 \\
\hline 9. & 3.2 & 5 \\
\hline 10. & 3.4 & 5 \\
\hline 11. & 4.2 & 2 \\
\hline 12. & 2.6 & 4 \\
\hline
\end{tabular}




\begin{tabular}{|c|c|c|}
\hline 13. & 2.4 & 3 \\
\hline 14. & 2.0 & 3 \\
\hline 15. & 4.8 & 5 \\
\hline 16. & 3.0 & 3 \\
\hline 17. & 3.0 & 4 \\
\hline 18. & 3.0 & 3 \\
\hline 19. & 3.2 & 5 \\
\hline 20. & 3.2 & 3 \\
\hline 21. & 2.6 & 3 \\
\hline 22. & 3.0 & 5 \\
\hline 23. & 2.8 & 3 \\
\hline 24. & 3.0 & 3 \\
\hline 25. & 2.8 & 3 \\
\hline 26. & 2.6 & \\
\hline $\mathrm{r}$ & \multicolumn{2}{|l}{0.1518} \\
\hline
\end{tabular}

It is vital to mention that even a strong correlation does not necessarily provide evidence of a mutual relationship between variables. Thus, the interpretation of variables is not straightforward and has (within our findings) a more informative character. The experiment can be considered a suitable illustration of the discussed issue.

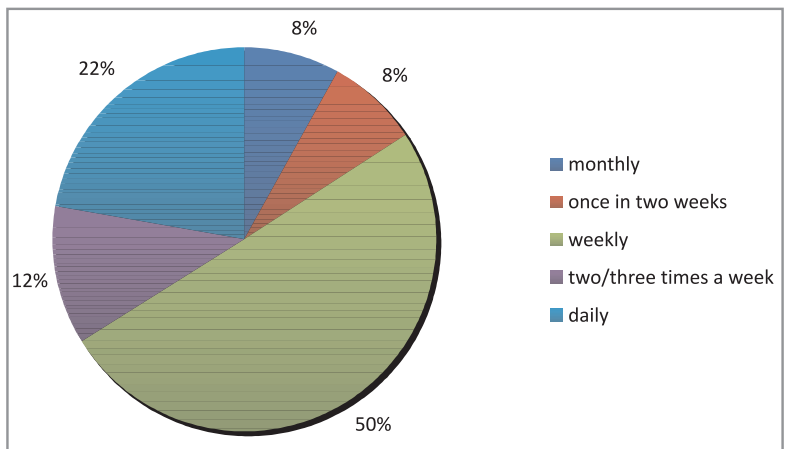

Fig. 1 Respondents' frequency of watching TV programmes

In Table 3 we can see that the average score of the respondents' pronunciation is 3.08. The native speakers' evaluation of the English pronunciation of our respondents indicates that their command of pronunciation is between "satisfactory" and "good". However, we must point out the fact that the topic was autobiographical and if a more difficult and abstract topic had been chosen, the quality of the pronunciation probably would have been lower. In Table 3 we can also find information about the frequency of watching TV programmes in English. The most important fact is that all of our respondents do watch TV programmes at least once a month. As we can see in Fig. 1, most of the respondents watch TV programmes on a weekly basis $(50 \%)$. We consider relevant that $22 \%$ of the respondents watch TV programmes regularly on a daily basis. The main reason stated by them is to improve their overall command of English.

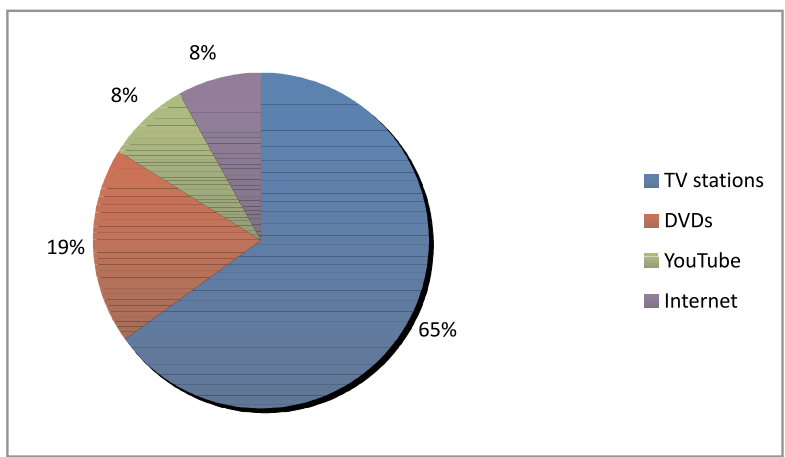

Fig. 2 Distribution of respondents according to the source used

According to Fig. 2, the overwhelming majority of our respondents watch TV programmes via satellite $(65 \%)$, as they are able to receive the overseas signal. They claimed to watch $\mathrm{BBC}, \mathrm{CNN}$, Sky News, Discovery Channel, Eurosport, CBS, FOX and NBC. $19 \%$ of them prefer watching these TV shows on original DVDs. This may be supported by the fact that there is a possibility of adding subtitles to the DVD. The remaining $16 \%$ like watching TV programmes on the internet. It is vital to highlight the fact that overseas transmission may be expensive and that students operate with a limited amount of money; therefore there may not be an opportunity for them to watch TV programmes from overseas TV stations because it could be over their budget.

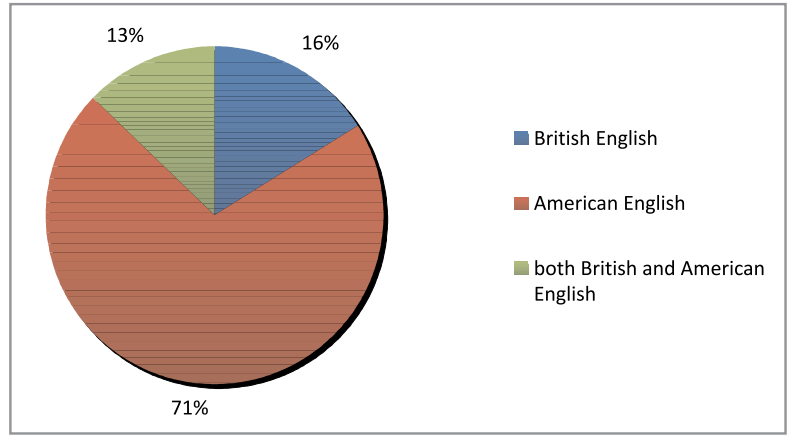

Fig. 3 Perceptual distribution according to the variety of English

As we can see in Fig. 3, the majority of our respondents watch TV programmes in American English. This may be due to the overwhelming influence of the entertainment, film and music industry of the United States of America. American shows are immensely popular and are well known all over the world. There are many television networks with plenty of quality programmes; therefore, there is a considerable amount of competition which may result in a higher number of quality TV programmes which may overshadow TV shows from other parts of the world where English is spoken. We would also like to point out the fact that none of our respondents reported watching TV programmes in Australian English, Canadian English or New Zealand English which resulted in the fact that all of them watch TV programmes in American English, British English or both. 


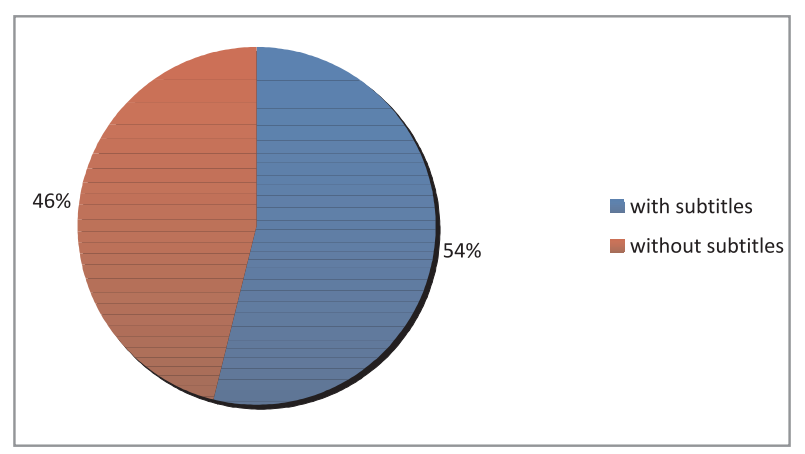

Fig. 4 Distribution of respondents according to subtitles used

Fig. 4 provides information on watching TV programmes with or without subtitles. The distribution is almost equal. Respondents who claimed watching TV programmes with subtitles usually use English subtitles. It is believed to be more efficient than using, for instance, Slovak subtitles. Learners have the opportunity to see, in real time, how the word is spelt, which is one of the advantages when using English subtitles.

Another advantage is when a student encounters a totally new word they have an instant opportunity to search for the word in a dictionary. Not only do they have a chance to see pertinent and extra information about the word, but they also can see the phonetic transcription and hear British or American pronunciation. Furthermore, they can try to pronounce the word on their own which may lead them to pronunciation practice.

However, using subtitles during watching TV programmes may be tricky. Many times while watching TV programmes, learners concentrate only on subtitles instead of what the actors are saying. They are being supported by the subtitles and are not worried when they do not understand the spoken text because they can easily read what actors say on the screen by looking at the subtitles. We may consider this phenomenon to be a way of cheating because in a real-life communication no subtitles are available. In addition to this, if the learners had only been watching TV programmes without subtitles, and had been using subtitles with more sophisticated or complicated language, their understanding might have improved faster. Furthermore, without subtitles the learners can only rely on their own ears and therefore, they must carefully listen to every single word and how it is pronounced which may lead to a slight increase in their own pronunciation accuracy.

Another issue emerges, when using subtitles, that is the decision of whether to use English or Slovak (Czech) subtitles. Some of the respondents claimed to use Slovak subtitles, some English. The decision here is simple; the learner should preferably use English subtitles. As we mentioned earlier, most of the TV programmes use standard and perfect English which make it easier for a learner to understand. Using subtitles is recommended for a learner when they are not sure they understand the message or when they are dealing with more sophisticated, idiomatic, colloquial and complicated language.

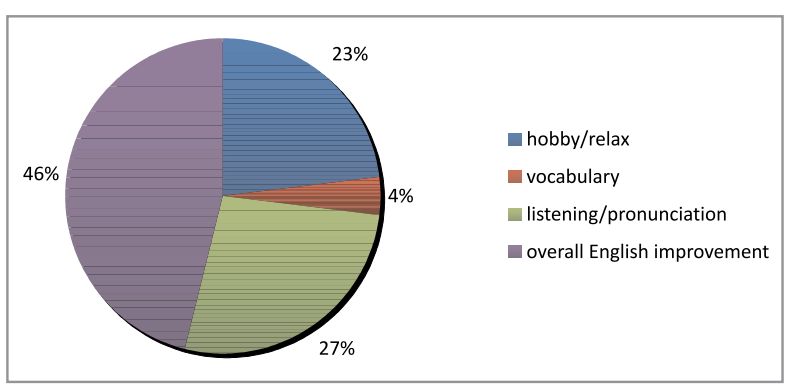

Fig. 5 Reasons for watching TV programmes

Fig. 5 indicates that most of our respondents watch TV programmes in order to increase their general command in English (46\%). This counts for listening, speaking, pronunciation, vocabulary, sentence structures, idiomatic expressions, cultural and social English background and others. 27\% of respondents state that their major concern in watching these programmes is due to listening and pronunciation improvement. They are trying to repeat the particular pronunciation what subsequently, may lead to better overall pronunciation. Only $4 \%$ of respondents watch TV programmes because of vocabulary building and $23 \%$ of them have no intention in elevating their overall English, vocabulary or listening/pronunciation, but they only watch TV programmes for relaxation or as a hobby.

\section{Conclusions}

Within our experiment, pronunciation of 26 students was recorded and subsequently evaluated by English native speakers. The average value 3.08 suggests that the overall pronunciation quality of respondents is between "satisfactory" and "good". This result can be considered an appropriate value based on the fact that respondents were in the first year of their studies.

We found out that the majority of our respondents watch TV programmes weekly. $22 \%$ of them watch TV shows on a daily basis, which may be considered to be an important finding because of an everyday exposure to speech produced by native speakers. Most of our respondents watch TV programmes on TV stations via satellite receivers. Two thirds of respondents are being exposed to American English. This may be due to the scope of US film industry. The main reason for watching is to be claimed to improve their overall English skills. Respondents believe that the more they watch English TV the better their overall improvement will be. The distribution of respondents according to whether they use subtitles during watching or not is almost equal. Both, watching with or without subtitles, have their advantages and disadvantages. However, we regard, mainly for higher levels (B2, C1), watching TV programmes without subtitles as more efficient and relevant.

The correlation coefficient indicates that the influence of watching TV programmes on pronunciation is not evident, which does not necessarily mean that there is no impact on one's pronunciation when they are being exposed to authentic English. We 
must, however, mention that a number of factors which cannot be measured could have played a minor role within our research. Elements, such as additional pronunciation practice of some respondents, further and more thorough study of English language at home, at language schools and at other institutions, or possibly a stronger interest in pronunciation issue than the majority of other students, studying the relevant materials and others might have influenced the research.

Despite this finding, we think that the influence of watching TV programmes makes some positive impact on one's pronunciation and also on general English knowledge when taking into consideration other aspects of language learning and acquisition, such as vocabulary, listening, phrases, idiomatic expressions and possible exposure to English produced by native speakers. Subsequently, watching authentic TV programmes is extremely popular among the students and learners of English. It may also be an excellent and educational way of relaxing.

Obviously, students agree that watching TV programmes is one of the most exciting parts of learning a foreign language. Excitement, fun and enjoying learning is one of the key factors in English language learning, because a student is being kept motivated. Plenty of dialogues use non-standard diction, which may cause frustration for beginners because they probably will not be able to understand exactly what is being said. Therefore, it is vital to make a correct decision when choosing an appropriate TV show. Learners are supposed to be taught standard pronunciation, and, of course, when they hear different speech and pronunciation, they might be confused. Students ought to acquire the standard pronunciation first before moving on to "television" language. Generally, we distinguish many TV programmes (among others): situation comedies, soap operas, serials, TV shows, reality shows, news, documentaries, music clips, weather forecasts and movies [3].

We may find a big advantage in authentic television programmes. They provide a learner with live language of various varieties in horizontal and vertical classification of the language (geographical and social varieties). Learners often identify themselves with their favourite characters and their stories and the effect of imitation of the $\mathrm{L} 2$ pronunciation is more significant.

In conclusion, we think that in the field of English language methodology, still more and more research should be done in order to reveal the most effective methods of pronunciation training and the most promising ways of pronunciation acquisition because the correct pronunciation, the one which approaches the level native speakers operate at and the one which seems to be so excruciatingly difficult to achieve, may be one of the significant factors of the communication in English language [4, pp. 315].

\section{References}

[1] KRALOVA, Z.: Factors of English Phonic Competence (in Slovak), Zilina, Edis, 2009, p. 94, ISBN 978-80-554-0051-8.

[2] MURCIA, M. C., BRINTON, D., GOODWIN, J.: Teaching pronunciation, New York, Cambridge University Press, 1996, p. 447, ISBN 978-0521406949.

[3] English Movies To Improve Your English? Not Recommended For Everybody. [cit. 2010-03-10], Available at: http://www.learningenglish.ca/english-movies-to-improve-your-english-not-recommended-for-everybody/

[4] GADUSOVA, Z., MALA, E., ZELENICKY, L.: New Competences in Slovak Teacher Training Programmes. In: TEPE Teacher Education Policy in Europe Network. Umea : University of Umea, pp. 313-323, ISBN 978-91-7264-600-1. 